\title{
Early detection of iron overload in the heart: a key role for MRI!
}

\author{
Leo H. B. Baur
}

Received: 6 November 2009/Accepted: 9 November 2009/Published online: 24 November 2009

(C) The Author(s) 2009. This article is published with open access at Springerlink.com

Hereditary haemochromatosis is autosomal recessive disorder associated with the HLA-A locus on the short arm of chromosome 6 [1]. It is the most common genetic disorder worldwide [2]. About 56,000 babies are born each year with thalassaemia major, of whom 30,000 require lifelong transfusions to survive [3]. The disease is very prevalent in European countries along the Mediterranean Sea and in South East Asia. In other countries it becomes a problem because of immigration from these areas. Excessive iron deposition occurs mostly in the pancreas, pituitary, but also in the heart. In normal subjects, absorption of iron from the gut is inversely correlated with iron stores. In homozygous hereditary haemochromatosis there is increased absorption of iron, which is not regulated by iron stores [4]. This leads to progressive iron accumulation because there is no normal mechanism for excretion of excess iron once it has been absorbed into the body. The clinical manifestations of iron overload include liver disease in $75 \%$ of cases, weakness and lethargy in $74 \%$, skin hyperpigmentation in $70 \%$, diabetes mellitus in $48 \%$,

Editorial comment on the article of Mavrogeni et al. (doi: 10.1007/s10554-009-9491-9).

L. H. B. Baur $(\bowtie)$

Department of Cardiology, Atrium Medical Centre

Parkstad, University of Maastricht, Henri Dunantstreet 5, 6401 CX Heerlen, The Netherlands

e-mail: 1br01@atriummc.nl arthralgia in $44 \%$, impotence in $45 \%$, electrocardiographic abnormalities in $31 \%$ and heart failure and conduction disturbances in $15 \%[5,6]$. Heart failure remains a major cause of death in these patients, frequently people younger than 35 years [7]. In the majority of patients iron induced cardiomyopathy can be reversed by intense chelation therapy with desferrioxamine and deferiprone [3, 8]. At this moment $\mathrm{T} 2 *$ magnetic resonance imaging is the best way for early detection of iron overload in patients with haemochromatosis [9-11]. T2* is an unique magnetic resonance parameter measured in milliseconds and shortened in relation to the level iron in the heart. The parameter can be used for screening haemochromatosis patients and to guide chelation therapy in those with established cardiac haemochromatosis [8]. The paper of Mavrogeni et al. [12] in this issue of the International Journal of Cardiac Imaging shows, that heart failure patients with severe iron overload indicated by a $\mathrm{T} 2 *$ value less than $10 \mathrm{~ms}$ had a lower exercise capacity than patients with a $\mathrm{T} 2 *$ value higher than $10 \mathrm{~ms}$. The authors also show, that there was a excellent relation of the extent of iron overload measured by $\mathrm{T} 2 *$ and exercise tolerance in thalassemia patients. As shown by others, thalassemia patients present prolonged phase II on-transient oxygen kinetics during submaximal, constant workload exercise, compared with healthy controls, possibly suggesting a slower rate of high energy phosphate production and utilization and reduced oxidative capacity of myocytes [13]. This could also 
account for their significantly limited exercise tolerance. Reduction of exercise tolerance is also s highly associated with the limited functional status of peripheral muscles in these patients [14]. This study shows again that T2* MRI plays a crucial role in screening cardiac haemochromatosis and guidance of chelation therapy. Early detection of cardiac iron load and early initiation of treatment are crucial for survival of these patients. Recently the chelator deferasirox has been shown to be more effective in better at improving myocardial iron [15]. This could improve outcome in thalassemia patients. As shown, early effects of therapy can only be detected with dedicated MRI sequences. Unfortunately these MRI scanners are not always available in those areas, where the prevalence of haemachromatosis patients is extremely high.

Open Access This article is distributed under the terms of the Creative Commons Attribution Noncommercial License which permits any noncommercial use, distribution, and reproduction in any medium, provided the original author(s) and source are credited.

\section{References}

1. Schrier SL, Bacon BR (2008) Clinical manifestations of hereditary chromatosis. Uptodate: www.uptodateonline. com

2. Weatherall DJ, Clegg JB (1996) Thalassemia-a global public health problem. Nat Med 2:847-849

3. Carpenter J-P, Prasad SK, Penell DJ (2009) Myocardial fibrosis in thalassaemia: recalling the past or telling the future? Heart 95:448-449

4. Lynch SR, Skikne BS, Cook JD (1989) Food iron absorption in idiopathic hemochromatosis. Blood 74:21872193

5. Niederau C, Strohmeyer G, Stremmel W (1994) Epidemiology, clinical spectrum, and prognosis of hemochromatosis. Adv Exp Med Biol 356:293-302

6. Rivers J, Garrahy P, Robinson W, Murphy A (1987) Reversible cardiac dysfunction in hemochromatosis. Am Heart J 113:216-217
7. Bogna-Pignatti C, Rugolotto S, De Stephano P, Zhao H, Cappellini MD, Del Vecchio GC, Romeo MA, Forni GL, Gamberini MR, Ghilardi R, Piga A, Cnaan A (2004) Survival and complications in patients with thalassemia major treated with transfusion and desferoxamine. Haematologica 89(10):1187-1193

8. Pepe A, Lombardi M, Positano V, Cracolici E, Capra M, Malizia R, Prossomariti L, De Marchi D, Midiri M, Maggio A (2006) Evaluation of the efficacy of oral deferiprone in beta-thalassemia major by multislice multiecho T2*. Eur J Haematol 76(3):183-192

9. Anderson LJ, Holden S, Davis B, Presscott E, Charrier CC, Brunce NH, Firmin DN, Wonke B, Porter J, Walker JM, Pennell DJ (2001) Cardiovascular T2 star (T2*) magnetic resonance for the early diagnosis of myocardial iron overload. Eur Heart J 22:2171-2179

10. Pepe A, Positano V, Santarelli MF, Sorrentino F, Cracolici E, De Marchi D, Maggio A, Midiri M, Landini L, Lombardi M (2006) Multislice, multiecho T2* cardiovascular magnetic resonance for detection of the heterogeneous distribution of myocardial iron overload. J Magn Reson Imaging 23:662-668

11. Pepe A, Positano V, Capra M, Maggio A, Pinto CI, Spasiano A, Forni G, Derchi G, Favilli B, Rossi G, Gracolici E, Midiri M, Lombardi M (2009) Myocardial scarring by delayed enhancement cardiovascular magnetic resonance in thalassaemia major. Heart 95:489-494

12. Mavrogeni S, Gotsis E, Verganelakis D, Berdousis E, Dritsas A, Kokovou G, Toulas P, Ladis V (2009) Effect of iron overload on exercise capacity in thalassemic patients with heart failure. Int J Cardiac Imaging 25. doi:10.1007/ s10554-009-9491-9

13. Vasileiadis I, Roditis P, Dimopoulos S, Ladis V, Pangalis G, Aessopos A, Nanas S (2009) Impaired oxygen kinetics in beta-thalassaemia major patients. Acta Physiol (Oxf) 196(3):357-363 (Epub 2008 Nov 27)

14. Nanas S, Vasileiadis I, Dimopoulos S, Sakellariou D, Kapsimalakou S, Papazachou O, Tasoulis A, Ladis V, Pangalis G, Aessopos A (2009) New insights into the exercise intolerance of beta-thalassemia major patients. Scand J Med Sci Sports 19(1):96-102 (Epub 2008 Feb 27)

15. Neufeld EJ (2006) Oral chelators deferasirox and deferiprone for transfusional iron overload in thalassemia major: new data, new questions. Blood 107(9):3436-3441 